proposed by our critics. The dramatic difference observed strongly suggests different defects in the two patients and we would still maintain that secondary inhibition of $p$-hydroxyphenylpyruvic acid hydroxylase is by far the most plausible explanation in this patient and indeed in the patient with deficient soluble aminotransferase originally described by our critics.

In summary, we acknowledge the existence of certain weak- nesses in our report and indeed these were already acknowledged in the report itself. However, none of the criticisms raised seem to seriously affect the main observation of striking heterogeneity within patients with tyrosinemia of a type which does not cause liver damage (tyrosinemia type II, in the terminology of Dr. Buist and colleagues).

\title{
Letter to the Editor: Importance of Technique in the Induction of Glucuronyl Transferase in Gunn Rats
}

\author{
JOSEPH KRASNER \\ Department of Pediatrics, State University of New York, The Children's Hospital, Buffalo, New York, USA \\ ANIL B. MUKHERJEE \\ Section on Biochemical and Developmental Genetics, National Institute of Child Health and Human \\ Development, National Institutes of Health, Bethesda, Maryland, USA
}

We read with interest an article by Van Houwelingen and Arias entitled, "Attempts to Induce Hepatic Uridine Diphosphate-Glucuronyl Transferase in Genetically Deficient Gunn Rats by Normal Liver Tissue," which appeared in Pediatric Research $(8)$. These authors apparently failed to reproduce the results of our investigation (4). It is not surprising that the authors did not reproduce the results of our experiments as there seem to be some vital discrepancies between the methodologies of the two investigations as the following paragraphs will elucidate.

One of us (J.K.) supplied six Gunn rats to the above investigators (not eight as erroneously reported). Out of those six, two rats (a mating pair) were heterozygous. Van Houwelingen and Arias (see Table 1, Reference 8 ) were unable to detect any enzyme activity in any of the rats provided, although they should have found activity in at least two out of the six rats. One of us (J.K.) also had an opportunity to witness some of the grafting procedures of the above investigators and felt that their animals were kept too long under ether anesthesia. This is relevant, as we found (5) that best results were obtained when the entire procedure was completed within a short time $(10$ min) and with minimal anesthesia.

Since our initial report in Science (4), we have completed some additional investigations with the Gunn rats (5), basically to answer two questions: 1) how important was the time factor and 2) what proportion, if any, of the grafted cells survived in the recipient Gunn rat liver. The results of these studies indicated that $0.9 \%$ of the prelabeled grafted cells survived at least 12 weeks after transplantation, if the surgical procedure was limited to $10 \mathrm{~min}$. However, procedures requiring more than $10 \mathrm{~min}(15-30 \mathrm{~min}) \mathrm{had} 0.02$ and $0.01 \%$ cells, respectively, surviving at 12 weeks.
We proposed previously that one of the mechanisms of enzyme induction in the post-transplant Gunn rats could be due to a small number of grafted cells surviving in the recipient. These cells, in turn, produced enzyme with $100 \%$ efficiency (4). We do not have any direct evidence at this time. However, the finding that $0.9 \%$ cells survive in the recipient liver strongly supports our hypothesis. A long transplantation procedure affects the survival of the donor cells in the recipient liver. This is one of the possibilities accounting for the inability of the above authors to detect any enzyme activity.

Recently, we have been investigating the effects of the inhibitors of protein synthesis in the transplanted Gunn rats (unpublished data) using the same experimental design as reported previously (4). The grafted animals without antimetabolite treatment had enzyme activity (range $12-75 \mu \mathrm{mol}$ bilirubin glucuronide $/ \mathrm{min} / \mathrm{ml}$ homogenate) as reported earlier (4). These assays were done by different workers than the ones who did the original experiments and as previously, they had no prior knowledge of the origin of the liver tissues before the assays were performed.

Additionally, the fact that no enzyme activity was detected by the above authors (8) with either glucuronidation and/or glucosidation should have aroused suspicion as to the viability of the microsomal preparations since both of these enzymes are microsomal in origin. It has been reported for the rat that the glucosyl transferase for bilirubin is a different and a separate enzyme from glucuronyl transferase $(2,7)$. The Gunn rat has been shown to have both glucosyl transferase as well as glucuronyl transferase enzyme for $o$-aminophenol acceptor (6) (although bilirubin glucuronyl transferase is absent). This is particularly demonstrable when microsomes are activated by digitonin treatment (1). It would have been of much value if the liver 
homogenates from the Gunn rats used by the said authors were tested for enzyme activity utilizing the $o$-aminophenol acceptor. This would have indicated that their microsomal preparations were good and that their assay system was working.

Furthermore, Matas et al. (3) have shown a decrease in the serum bilirubin of homozygous Gunn rats after the infusion into the portal vein of isolated hepatocytes from the heterozygous Gunn rats. This finding essentially confirms our previous observations (4). Unfortunately, however, no reference to this report was made in the publication of Van Houwelingen and Arias.

\section{REFERENCES AND NOTES}

1. Heirwegh, K. P. M., deVijven, M. V., and Fevery, J.: Assay and properties of digitonin-activated bilirubin uridine diphosphate glucuronyl transferase from rat liver. Biochem. J., 129: 605 (1972).

2. Marniemi, J.: Bilirubin UDP-glucosyl and UDP-glucuronasyl transferase of rat liver: A comparative study of the effects of membrane perturbants in vitro and of chrysene administration in vivo. Chem. Biol. Interact., 9: 135 (1974).

3. Matas, A. J., Sutherland, D. E. R., Steffes, M. W., Mauer, S. M., Lowe, A., Simmons, R. L., and Najarian, J. S.: Hepatocellular transplantation for metabolic deficiencies: Decrease of plasma bilirubin in Gunn rats. Science, 192: 892 (1976).

4. Mukherjee, A. B., and Krasner, J.: Induction of an enzyme in genetically deficient rats after grafting of normal liver. Science, 182: 68 (1973).
5. Mukherjee, A. B., and Krasner, J.: Survival of transplanted normal hepatocytes in Gunn rat liver. (Manuscript in preparation.)

6. Mulder, G. J.: Bilirubin and the heterogeneity of microsomal uridine diphosphate glucuronyl transferase from rat liver. Biochim. Biophys. Acta, 289: 284 (1972).

7. Vaisman, S. L., Lee, K. S., and Gartner, L. M.: Xylose, glucose and glucuronic acid conjugation of bilirubin in the newborn rat. Pediat. Res., 10: 967 (1976).

8. Van Houwelingen, C. A. J., and Arias, I. M.: Attempts to induce hepatic uridine diphosphate-glucuronyl transferase in genetically deficient Gunn rats by grafting of normal liver tissue. Pediat. Res., 10: 830 (1976).

9. Correspondence should be addressed to: Anil B. Mukherjee, M.D.. Section on Biochemical and Developmental Genetics, NICHHD, NIH, Bethesda, MD 20014 (USA).

\section{ADDENDUM}

Since we submitted a letter to you on April 29, 1977 in response to a paper by Van Houwelingen and Arias we noted two publications in support of our initial observations. These references are as follows:

Groth, C. G., Arborgh, B., Bjorken, C., Sundberg, B., and Lundgren, G.: Correction of hyperbilirubinemia in the glucuronyl transferase-deficient rat by intraportal hepatocyte transplantation. Transplant. Proc., 9: 313 (1977).

Sutherland, D. E. R., Matas, A. J., Steffes, M. W., Simmons, R. L., and Najarian, J. S.: Transplantation of liver cells in an animal model of congenital enzyme deficiency disease. Transplant. Proc., 9: 317 (1977).

\title{
Letter to the Editor: Reply to Drs. Mukherjee and Krasner
}

\author{
IRWIN M. ARIAS
}

Liver Research Center, Albert Einstein College of Medicine, Bronx, New York, USA

Dr. Van Houwelingen and I reproduced, to the best of our ability and knowledge, the experiments published by Mukherjee and Krasner (Science, 1973). To this end, we appreciate Dr. Krasner's participation in the surgical procedure, including anesthesia. The rats were all homozygous (ji) Gunn rats which were provided either by Dr. Krasner or the Einstein Animal Institute. Each Gunn rat had unconjugated hyperbilirubinemia and no measurable UDP-glucuronyl transferase in liver preparations with bilirubin as a substrate.

Loss of "microsomal viability" in our assay system is unlikely.
1) Microsomal preparations from normal and ij rats were treated identically; the former had abundant bilirubin glucuronidation and glucosidation, and the latter had none. 2) Bile duct cannulation of transplant recipient rats failed to reveal bilirubin glucuronide (or other major conjugates). This is the most sensitive index of bilirubin conjugation in vivo.

Presentation of data demonstrating that anesthesia time (10 min versus $15-20 \mathrm{Min}$ ) is critical for successful implantation of liver tissue and for UDP-glucuronyl transferase "induction" is the next reasonable step to be taken. 